\title{
Quantitative Analysis of Regional Luxury Brand Marketing Using Logit Model
}

\author{
Xianfeng Chen $\mathbb{1}$ \\ School of Business Administration, Henan University of Animal Husbandry and Economy, Zhengzhou, Henan 450044, China \\ Correspondence should be addressed to Xianfeng Chen; 81364@hnuahe.edu.cn
}

Received 20 December 2021; Revised 17 January 2022; Accepted 20 January 2022; Published 10 February 2022

Academic Editor: Miaochao Chen

Copyright (C) 2022 Xianfeng Chen. This is an open access article distributed under the Creative Commons Attribution License, which permits unrestricted use, distribution, and reproduction in any medium, provided the original work is properly cited.

The luxury consumer market in my country is developing rapidly. However, due to the differences in the culture and consumer psychology of different regions in my country, the marketing status of luxury goods in my country will be different in different regions. Under the premise of analyzing consumer groups, it deeply analyzes the factors that affect the luxury consumption psychology of Chinese consumers, expounds this psychological state, and then analyzes the problems existing in my country's luxury goods marketing. Finally, based on consumer psychology, suggestions on luxury marketing related to these issues have been put forward. In addition, quantitative research on marketing and how to psychologically open a new chapter of marketing in the luxury goods industry have always been the core themes that foreign marketing researchers will continue to explore for a long time. The logo model is an excellent analysis in this process. By introducing the principles of the logo model and applying this model to the empirical study of domestic consumers' choice of a specific luxury brand, it is shown that the logo model can be used to analyze many problems in marketing research. More useful quantitative information is undoubtedly of great benefit to the academic research of marketing and the practice of marketing management.

\section{Introduction}

The logistic model, also known as the logistic regression model, is a discrete choice model gradually developed abroad in the first half of the twentieth century. It has been widely used in biology, economics, psychology, political science, and transportation [1]. Logo model is a type of econometric model widely used in economics to study the selection process of actors. The starting point of the logit model analysis is the causal view; that is, the appearance of a behavior or a choice result must be caused by a combination of many factors [2]. The application field of the logo model is very extensive. In marketing research, especially the quantitative analysis of regional luxury brand marketing, as long as consumers choose or rank different alternatives, they can use the logo model for analysis [3]. In the era of the global information explosion, luxury goods have increasingly entered the public's field of vision. The consumption power of Chinese luxury goods has become a leading international level. With the globalization of luxury goods, and more and more luxury goods are accepted and yearned by the general public $[4,5]$. The traditional logit model usually selects multiple different indicators to see the impact of different indicators on consumer brand choices. Through practice, it is found that a large number of indicators will produce multicollinearity problems. In this regard, in order to reduce the impact of multiple different indicators, people often use a small number of indicators to obtain a large amount of equivalent information. Multiple logit models are currently commonly used models in brand selection. They are based on the theory of maximum utility and use a certain brand as a reference to compare different product brands in pairs to form a selection set $C$. In this selection set, each brand has a certain effect on consumers. This article will apply the logit model to quantitatively evaluate the marketing effects of luxury brands based on the observation data collected from consumers buying a luxury brand in a business place [6-9].

Existing foreign documents within the scope of the research subject of this article are rich in both qualitative and quantitative research. There is a lot of domestic literature on 
qualitative research and practice summary, but there is little literature on quantitative research on sales promotion [10]. The literature of qualitative research mainly focuses on the consumer behavior basis of sales promotion and the concepts, methods, and management of sales promotion, which constitute the theoretical basis of sales promotion [11]. Foreign literature on quantitative research on sales promotion basically applies econometric models to process the collected data and then analyzes the results of the model to evaluate the impact of sales promotion on indicators such as brand, sales, market share, and profit. Driven by the rapid development of China's commodity economy and the advanced marketing concepts brought by multinational companies after entering China, China has gradually become in line with international standards in learning advanced foreign marketing theories, and companies are applying advanced marketing theories to domestic marketing practices. A lot of work has also been done [12]. Figure 1 shows a schematic diagram of the conceptual model of envy and desire for luxury consumption. Based on consumer purchase data collected in shopping malls, this article analyzes the quantitative research and analysis of regional luxury brand marketing. The logit model fits the observation data of luxury purchases used in this article very well. This shows that in the absence of system data support in China, applying the model to this simple data can still effectively evaluate the impact of marketing [13]. All marketing methods contribute positively to market share growth, but there are significant differences in the magnitude of their contribution or marketing effectiveness. In practice, the most frequently used method is not the most effective method. This means that the return on marketing investment may not be optimal, and sales promotion decisions need to be further improved [14]. In recent years, luxury e-commerce has gradually risen. Besides, online sales of luxury goods have grown rapidly thanks to high-quality stock, e-commerce, and time-limited marketing. Therefore, e-commerce marketing has formed a good synergistic relationship with luxury sales.

\section{The Important Role of Digitalization in Luxury Marketing}

Digital new media is the revolutionary direction of future marketing. Nowadays, most brand companies have adopted digital marketing methods more or less in their marketing. Traditional marketing pays more attention to the sales funnel model by attracting people's attention, actively promoting products and services to people, persuading people why this is the first choice, and then motivating people to actually buy. Today, such a model can no longer produce good results. Hold an offline TV marketing event that attracts people's attention. Consumers will not flood into physical stores but instead flood into the Internet [15]. Marketing is shifting from multichannel marketing to allaround marketing. Jason Bloomberg mentioned in Forbes in 2014 that digitization is not just the use of the Internet and media. It represents the connection between the touchpoints, and it hides the differences between the various
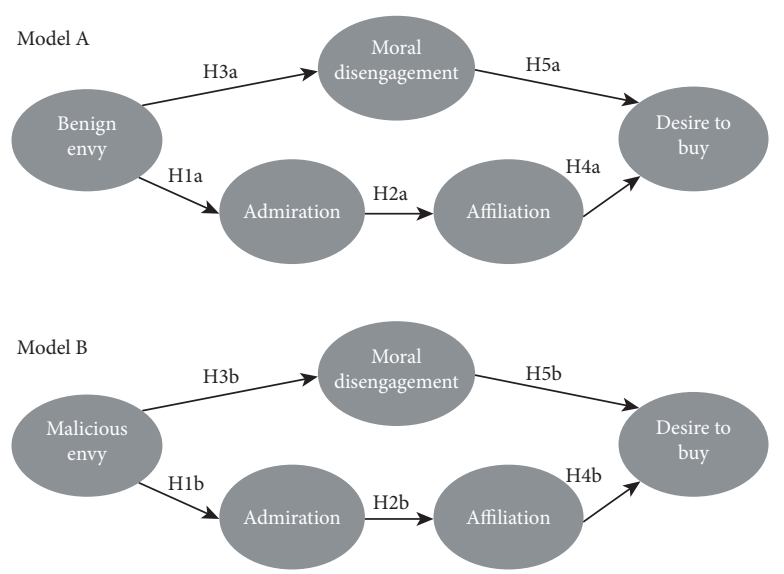

FIgURE 1: Schematic diagram of the concept model of envy and desire for luxury consumption.

channels from the consumer's point of view. To accurately understand the online behavior of consumers and improve brand marketing strategies accordingly, it is necessary to conduct a scientific and effective analysis of the collected online behavior data of consumers. This is also the way for brand companies to defeat their opponents in the current fiercely competitive market, which is one of the essential factors for success. Marketing in the digital age actually refers to a series of activities in that companies use communication technology, computer technology, and artificial intelligence technology to promote product sales to conduct various surveys, publicity, plans, business philosophy dissemination, and guide consumer trends on marketing objects and behaviors [16]. The performance graph of the dataset processed by clustering is shown in Figure 2 . Marketing in the digital age requires companies to focus on marketing strategies as the main target, while focusing on the ingenious integration and application of the advantages of digitization and networking, intelligence, and visualization with marketing. For data mining, the fuzzy C-means clustering algorithm is constructed for data processing as an important tool to conduct consumer behavior analysis. The consuming behavior of luxury brands is identified and classified through big data [17].

Compared with traditional algorithm, the fuzzy c-means clustering algorithm is a kind of unsupervised algorithm for its simplicity and fast speed. Therefore, adaptive clustering does not need to set a specific value in advance. The digital marketing studied in this article is mainly based on the network world, through the use of large amounts of data, using digital media, to achieve maximum marketing and quantifiable marketing effects. Data can be used to achieve extraordinary results. In the era of big data, this new type of marketing has appeared: digital marketing, with its distinctive features and different marketing methods that have appeared before. Digital marketing digs out the data behind consumers and customizes a strategy suitable for most people [18]. Digitization also brings some challenges to business managers in the design and implementation of international marketing strategies. For example, digitalization requires companies to accept new changes. In order to 

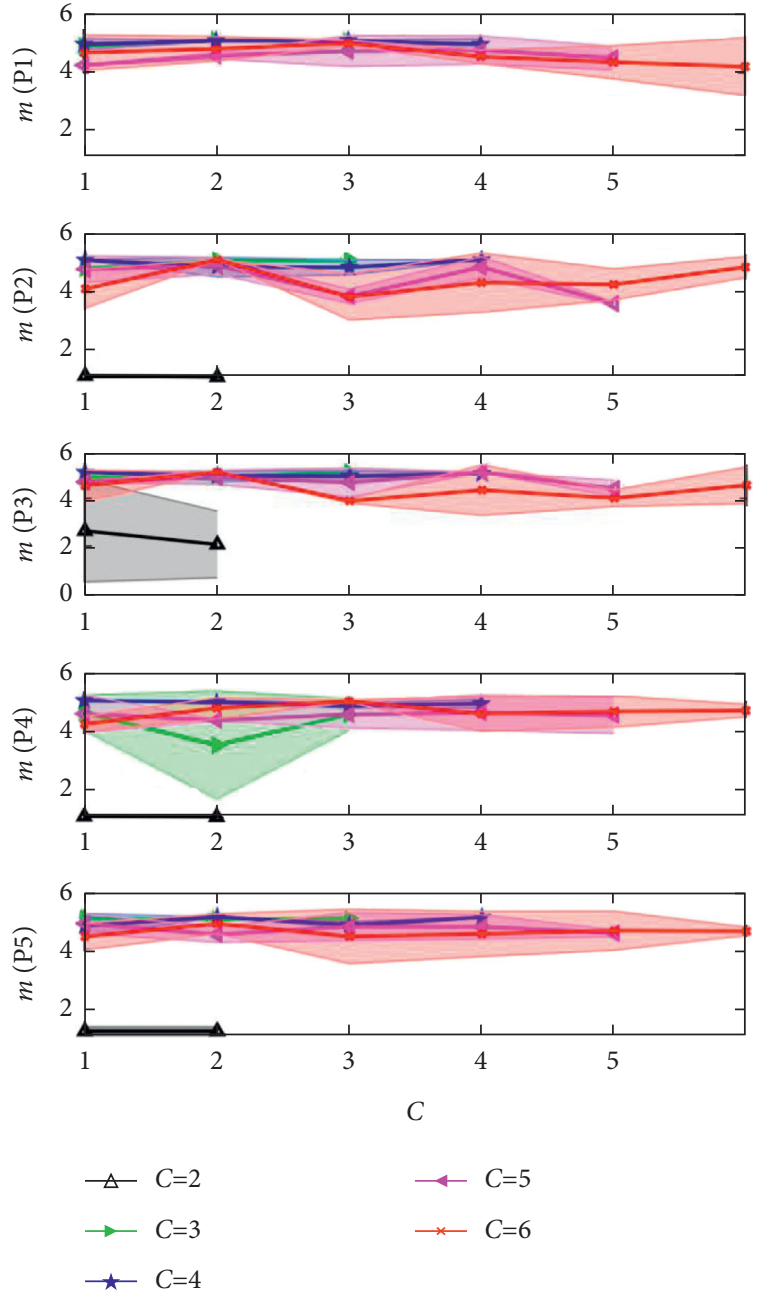

Figure 2: Performance of the dataset through clustering processing.

keep up with the general trend of digitalization, companies must maintain multiple touchpoints on various social media and digital platforms around the world. This requires companies to establish a fusion of technology and creativity-sales, marketing, service, and operations teams [19]. Digitization can allow buyers from all over the world to make suggestions and help companies develop new products and services online, thus occupying a major position in the marketing of luxury goods. Only by embracing the digital age and conducting more precise international marketing research can we take a more active position in the new competition [20]. The future of digital marketing is worth looking forward to, but it also needs to achieve transformation and development from a "people-oriented" perspective, better serve consumers, and improve quality and efficiency through digital management.

Compared with other industries, luxury brands lag behind in digital marketing, under the action of time. Many new media are appearing in luxury brand marketing. Figure 3 shows the distribution of different consumer groups of luxury goods. Among them, advertising, video, and mobile media are the growth rate, which is significantly higher than other fields [21]. Furthermore, the improved traditional collaborative filtering recommendation algorithm is studied, and fuzzy c-means (FCM) clustering and collaborative filtering algorithm are combined into the system. The recommendation algorithm selects the most interesting products from the set of alternative products according to certain rules to recommend. The digital marketing research of international mature luxury brands is of guiding significance for the future development of China's luxury market. Analyzing the development of mature foreign luxury brands is of great significance to the marketing and development of Chinese luxury brands.

\section{Logit Model Variable Setting and Research Hypothesis Analysis}

3.1. Multilogit Model. The variables determined by the multilogit model regression model can be correlated under a large number of observations. Besides, it can also be expressed by means of functional relations, called regression functions or regression equations. The multiple logit model, as a commonly used model in brand selection at present, is based on the theory of maximum utility and uses a certain brand as a reference to compare different product brands in pairs to form a selection set $C$. In this selection set, each brand has a certain effect on consumers. Consumers will only buy the brand that has the greatest utility to them. At the same time, consumers will be affected by many factors when choosing. Therefore, for consumers, the utility $U_{i j}$ of choosing brand $j$ can be expressed by the following formula [22]:

$$
U_{i j}=V_{i j}+\varepsilon_{i j}
$$

where $V_{i j}$ is the systematic item of total utility $U_{i j}$, reflecting the utility of brand selection factors observed by consumers, and $\varepsilon_{i j}$ represents the random utility observed by consumers, which represents the error term.

When consumers choose a brand, they usually face not only one brand but multiple brands, $j=1,2,3, \ldots, J$. Therefore, the multiple logit models of the brand can be expressed as follows [23]:

$$
L\left(P\left(y_{i}=j_{x}\right)\right)=\frac{e^{\alpha_{j}+\sum_{k=1} \beta_{j k} X_{i j k}}}{1+\sum_{j=1}^{j-1} e^{\alpha_{j}+\sum_{k=1} \beta_{j k} X_{i j k}}} .
$$

For consumers, they will always choose the most effective brand solution. Therefore, the probability of consumers choosing brand $k$ can be expressed as follows:

$$
P_{i}(k)=\left(U_{i k} \geq U_{i j}, j \neq k\right) \text {. }
$$

Hennigs et al. found through analysis that the traditional multilogit model usually selects multiple different indicators to see the impact of different indicators on consumer brand choices [24]. Through practice, it is found that a large number of indicators will produce multicollinearity problems. In this regard, in order to reduce the impact of multiple different indicators, people often use a small number of indicators to obtain a large amount of equivalent 


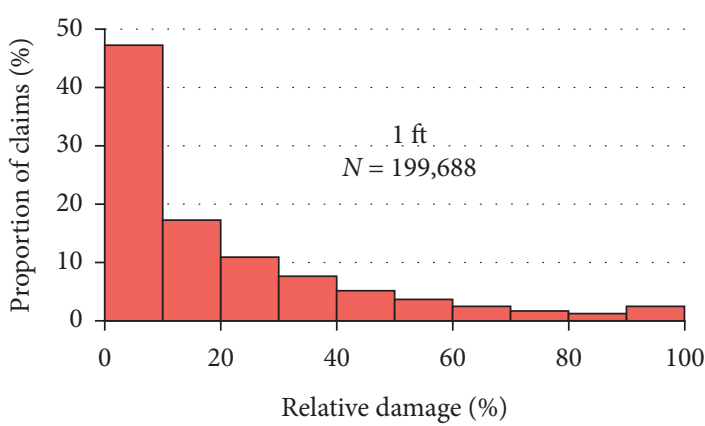

(a)

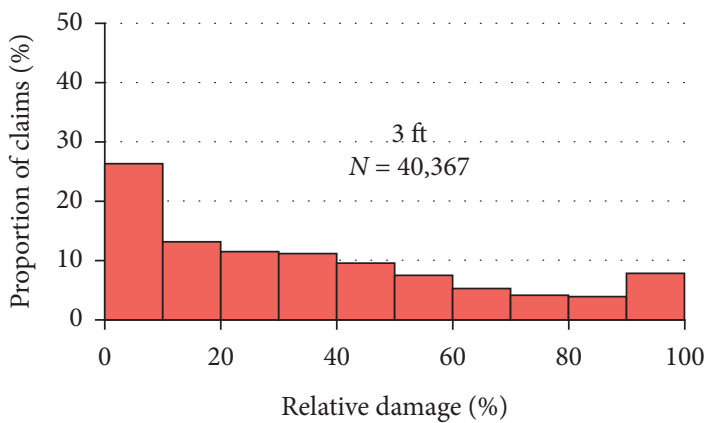

(c)

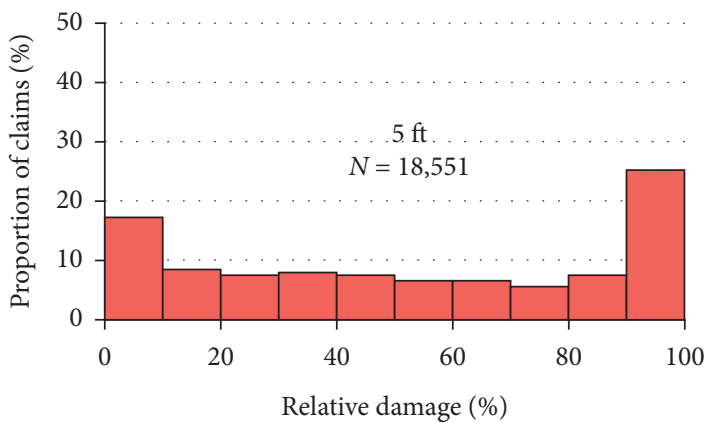

(e)

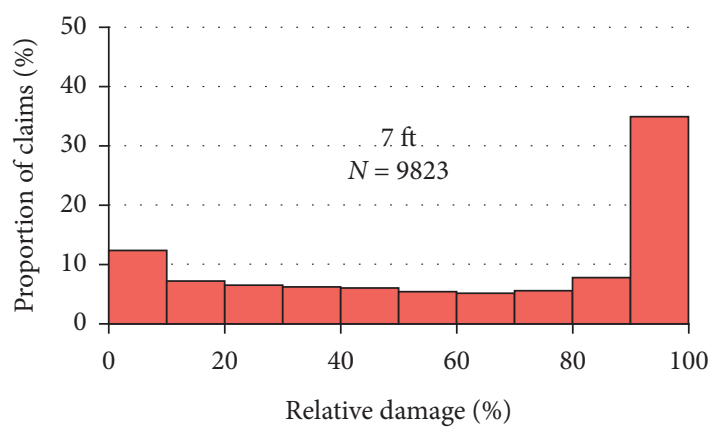

(g)

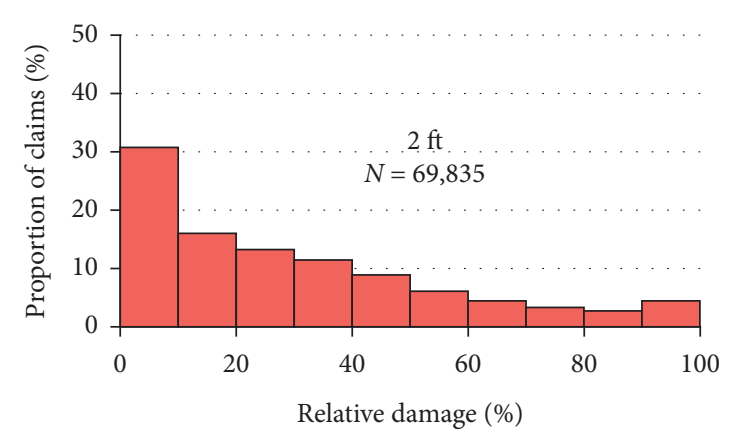

(b)

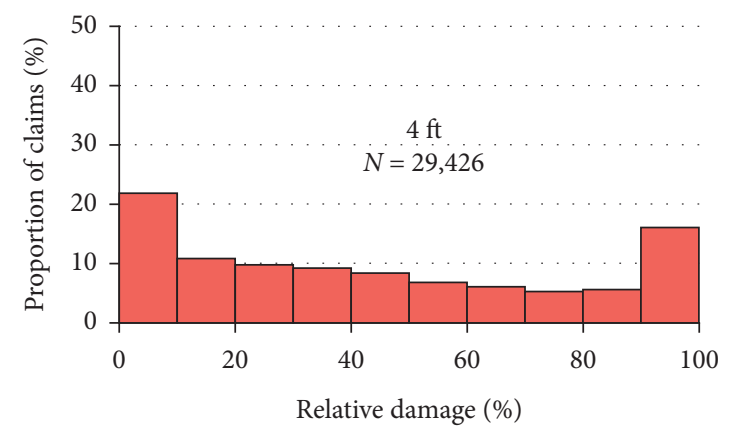

(d)

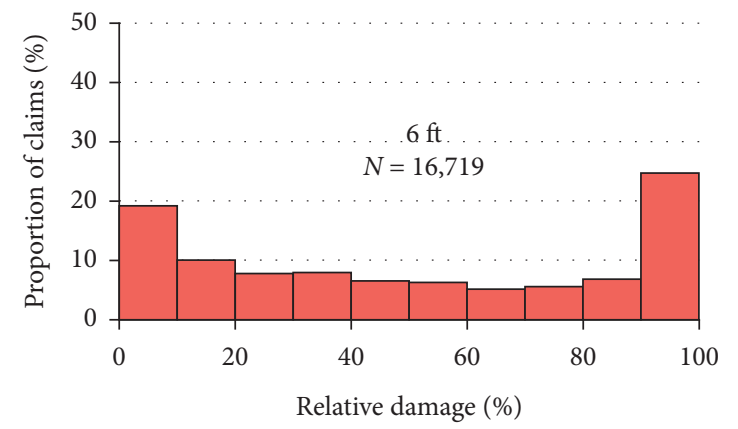

(f)

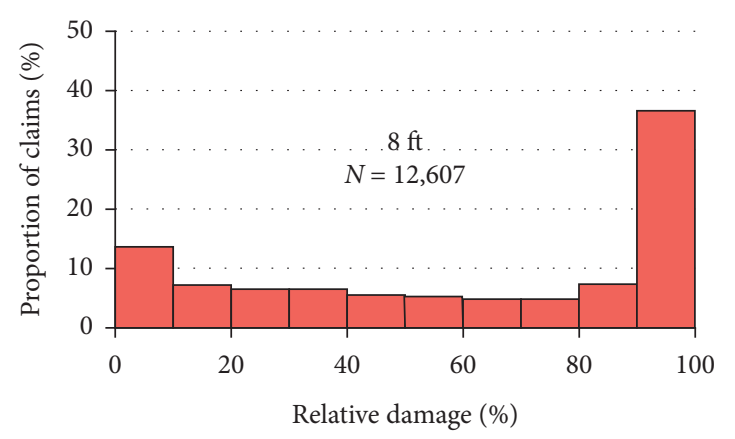

(h)

Figure 3: The distributions of different consumer groups of luxury goods.

information. Moreover, this kind of thinking is called principal component analysis. Specifically, by constructing the correlation matrix between the selected variables, the principal component indicators that can basically control the independent variables are found. For the selection of the principal component index, as much as possible, the independent variable information is included, and the correlation between the independent variables is reproduced by it so as to achieve the purpose of dimensionality reduction and simplify the calculation. The mean square error with iterations predicted by the clustering algorithm is calculated, as shown in Figure 4.

Professor McFadden theoretically proved that the probability of a consumer choosing a product from a 


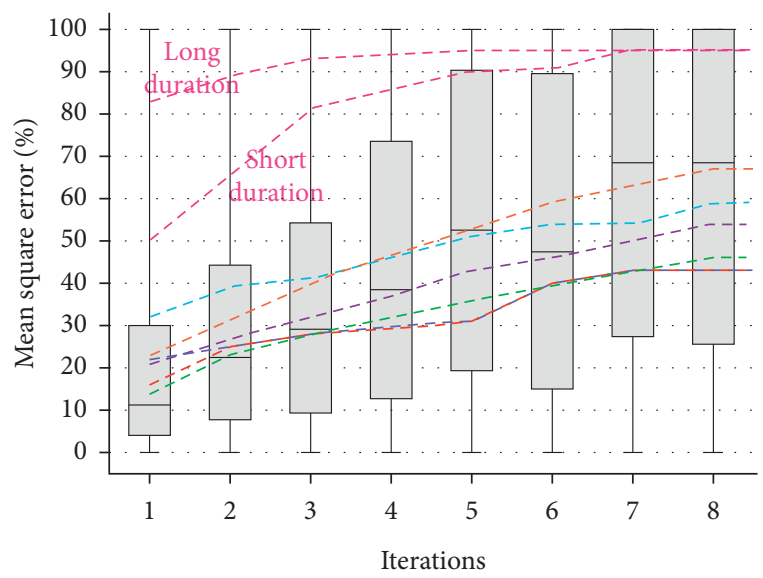

Figure 4: The mean square error with iterations predicted by the clustering algorithm.

selection set consisting of multiple different products can be expressed in a closed mathematical expression, which has laid a solid foundation for the wide application of the logit model. The logit model is the most widely used statistical model in contemporary marketing research [25].

For the random part of utility $\varepsilon_{i j}$, two assumptions of the logit model are as follows.

(1) $\varepsilon_{i j}$ is an independently distributed random variable.

(2) The probability variable obeys the double power function probability distribution, as follows:

$$
F_{i j}=F\left(\varepsilon_{n i} \leq \varepsilon\right)=e^{-e^{-\varepsilon}} \text {. }
$$

In the formula, the upper number is the power function that determines the partial utility of commodity $i$ and the corresponding lower number is the accumulation of the partial utility function of the total number of commodities selected collectively. The random part of the utility will be cleverly avoided, greatly simplifying the calculation process of the selected function.

As mentioned above, the determination of utility is partly determined by observable related variables of commodities, related variables of consumers, and other variables. Suppose that there are $K$ observable variables that jointly assess the determining part of the utility. Generally, we use linear equations to express the relationship between these variables and utility, as follows:

$$
V_{i j}=a_{j}+\sum_{k=1}^{K} b_{k} x_{n j k} \text {. }
$$

$x_{n j k}$ refers to common variables that exist in all brands. Here, common means that every brand has this variable, and these variables do not mean that their values are equal. $b_{k}$ is the parameter value or proportion weight corresponding to the $K$ th random variable. Therefore, the consumer flag $n$ is omitted from the formula. Substituting formula (5) into formula (4), the formula can be transformed into the following [26]:

$$
P_{i j}=\frac{e^{a_{j}+b_{k x_{i j k}}}}{\sum_{j=1}^{J} e^{a_{j}+b_{k x_{i j k}}}} .
$$

In the above formula, $x_{n j k}$ is a known observation value, $a_{j}$ and $b_{k}$ are unknown parameters and need to be estimated. We do not know the selection probability $P_{n i}$, but we know which product the consumer chooses to buy from the selection set. We use $Y_{n j}$ to represent the result of consumer $n$ 's choice. If consumer $n$ chooses product $j, Y_{n j}=1$; otherwise, $Y_{n j}=0$.

3.2. Influencing Factors of Luxury Brand Marketing. Considering that the logit model has high requirements for observations, the data sample selected in this article is panel data. Since the explained variables are discrete, a discrete panel data model needs to be established in selecting the model. The probability model is a mathematical model used to describe the relationship between different random variables, usually describing the mutual nondeterministic probability relationship between one or more random variables. There are two main types of distributed panel data models: one is the probability model and the other is the logit model. Since the Probit model is used under the condition that the random error term in the model is a standard normal distribution, the logit model has a lower use condition, so it has lower accuracy than the Probit model, but it is easier to use. At the same time, in order to make it easier to understand, this article will build a logit model of regional luxury brand marketing influence factors [27].

There are two different situations for setting research phenomena (for example, whether luxury brand marketing is successful or not). In order to regress this type of event, the qualitative variable $Y_{i t}$ is introduced as an explanatory variable. When an event occurs, $Y_{i t}=1$; on the contrary, $Y_{i t}=0$, and all predictable and certain parameters are $X_{i t}$. Since the probability of occurrence of any event is between 0 and 1 , the unobservable reference variable $Z_{i t}$ is used instead of the dependent variable $Y_{i t}$. When the estimated $Z_{i t}$ is greater than or equal to $0, Y_{i t}$ takes 1 ; otherwise, it takes 0 . Let uit be the random error. The main formula of the logit model is as follows:

$p\left(Y_{i t}=1\right)=p\left(Z_{i t} \geq 0\right)=p\left(u_{i t} \geq-\beta_{i} X_{i t}\right)=F\left(\beta_{i} X_{i t}\right)$.

As shown in the regression results in Table 1, total marketing value growth rate $\left(x_{1}\right)$, capital adequacy ratio $\left(x_{10}\right)$, publicity expenditure ratio $\left(x_{11}\right)$, brand endorsement expenditure rate $\left(x_{13}\right)$, loan-to-asset ratio $\left(x_{14}\right)$, net asset income rate $\left(x_{15}\right)$, capital fluctuation $\left(x_{17}\right)$, and seven explanatory variable indicators passed statistical tests at a significance level of $10 \%$, indicating that these factors have a significant impact on luxury brand marketing.

From Table 1, the regression equation can be derived:

$$
\begin{aligned}
Z_{i t}= & 2.93-24.98 X_{1}-125.09 X_{10}-109.33 X_{11} \\
& -11.34 X_{13}+9.9 X_{14}-18.2 X_{15}-0.07 X_{17} .
\end{aligned}
$$

Figure 5 is a performance test chart using Minimax-FCM on the dataset. It can be concluded from the virtual dependent variable theory that, unlike the general regression equation, equation (3) only expresses the influence of each 
TABLE 1: Regression results of logit model in the data panel.

\begin{tabular}{lccc}
\hline Explanatory variables & Coefficient estimate & Standard deviation & $Z$ test value \\
\hline Constant term $(c)$ & 2.93 & 0.15 & 0.57 \\
$x_{1}$ & -24.98 & 0.23 & -1.99 \\
$x_{10}$ & -125.09 & 0.38 & -2.49 \\
$x_{11}$ & -109.33 & 0.4 & -2.1 \\
$x_{13}$ & -11.34 & 0.18 & -1.89 \\
$x_{14}$ & 9.9 & 0.12 & 1.15 \\
$x_{15}$ & -18.20 & 0.09 & -1.7 \\
$x_{17}$ & -0.07 & 0.04 & -0.56 \\
\hline
\end{tabular}
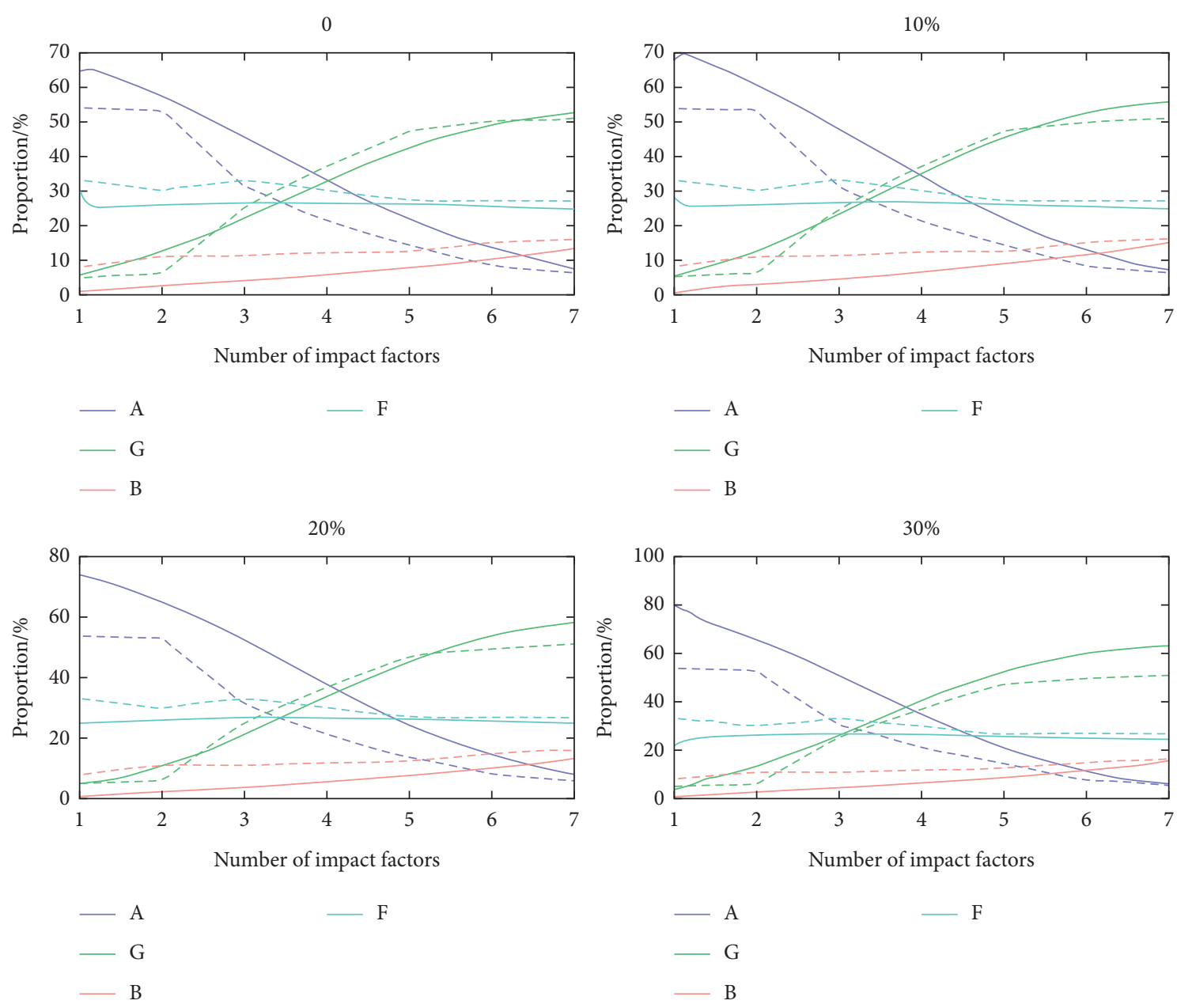

Figure 5: Performance of the test using Minimax-FCM on dataset.

explanatory variable on the reference index $Y_{i t}$, rather than the direct relationship between the explanatory variable and the dependent variable; however, the larger the $Z_{i t}$ value, the greater the probability that the dummy dependent variable $Y_{i t}$ takes 1, so this equation can indirectly indicate the influence of explanatory variables on the probability of regional luxury brand marketing events.

3.3. Nested Logit Model. According to the North-South trade model, enterprises in different regions compete with each other by making differentiated products and vertically differentiated products [28]. When the product contains both horizontal difference (such as type) and vertical difference (such as quality) characteristics, Schott's product unit value method (that is, when the product unit value is the same, the higher the market share, the higher the quality of the product) will be invalid. The phenomenon of "low price and high quality" appeared. For this reason, Berry took the lead in relaxing the strong assumption of "quality equals price" when analyzing consumer behavior in traditional supply and demand models and introduced quality into the consumer discrete choice model. Consumers' choice preferences are divided into horizontal 
difference preference and vertical difference. Preference: set the maximum indirect utility of consumer $i$ to purchase product $j$ as follows:

$$
u_{i j}=x_{j} \beta+\zeta_{j}-a p_{j}+v_{i j}
$$

In the formula, the explanatory variable $x_{j}$ represents the observable feature of product $j$ and $\zeta_{j}$ represents the unobservable feature (vertical difference preference, with quality as the main component)

Assuming that the level difference preference $v_{i j}$ satisfies the extreme value I-type distribution, the market share of product $j$ can be written in the well-known logit formula form:

$$
\begin{gathered}
s_{j} \equiv \frac{e^{\delta_{j}}}{\sum_{k=0}^{N} e^{\delta_{j}}}, \\
s_{0} \equiv \frac{1}{\sum_{k=0}^{N} e^{\delta_{k}}},
\end{gathered}
$$

where $k$ represents the product, and (10) and (11) take the logarithm and subtract them, respectively, to obtain the multinomial logit model established [29]:

$$
\operatorname{Ln}\left(s_{j}\right)-\operatorname{Ln}\left(s_{0}\right)=\delta_{j} \equiv x_{j} \beta-a p_{j}+\zeta_{j} .
$$

When there are a large number of similar products in the market, the unobservable characteristics obtained by the logit model after removing the observable features and price factors of the product may overestimate the quality of the product, resulting in a biased estimate. In order to make up for this defect, Khandelwal grouped similar products, allowing products in the same group to have related performance and characteristics. Figure 6 is a flowchart of the application algorithm. Consumers get the same utility from each product in the group, and the difference in market share of products in the same group comes from consumers' preference for horizontal disparity rather than vertical disparity, thus adding nested market share to the model.

In summary, the basic idea of using the nested logit model to measure the quality of a certain product can be summarized as follows: the market share of a certain product in the target market is the product price, the consumer level difference preference of the target market, and the product quality (vertical difference preference) and other factors. The idea of this model is theoretically applicable to most valuable normal commodities. This model is also applicable to luxury goods after removing the influence of nonvertical differences and hidden factors.

\section{Information of Evaluation Model}

Psychologist Luce and statistician Tukey proposed a joint analysis of Wind, Jain, and Green to introduce them into commercial applications and achieved good results. Conjoint analysis quickly occupied the consumer research market with its special advantages and was favored by the market.

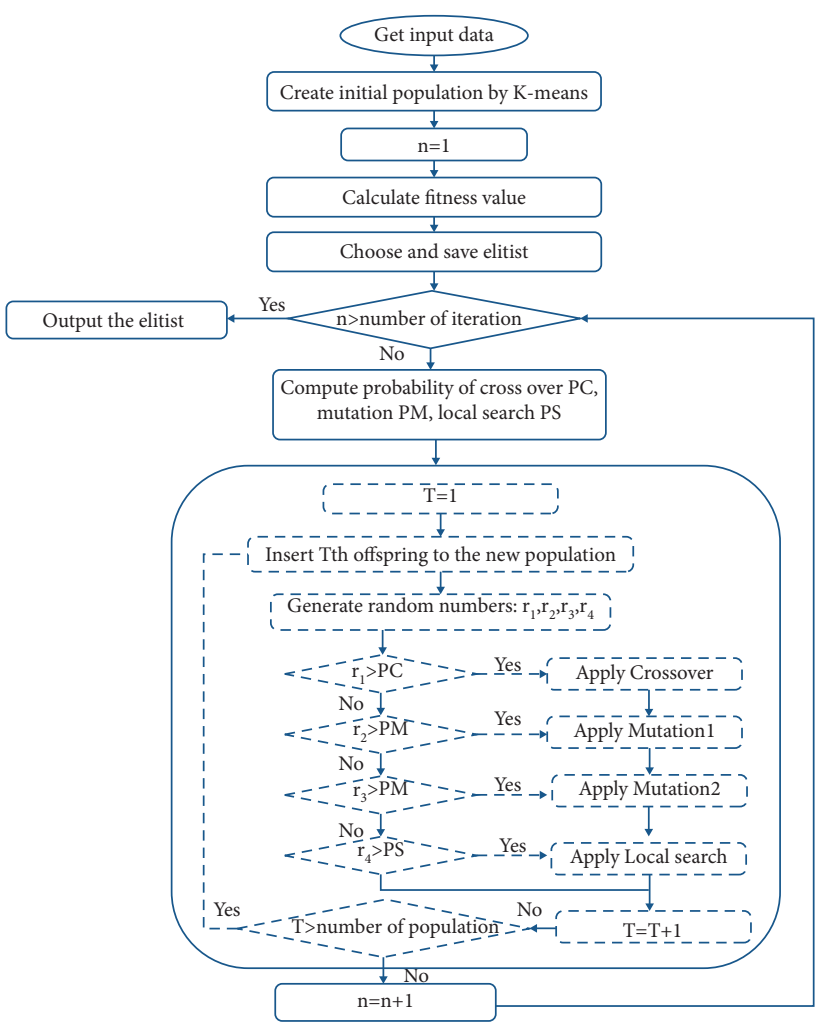

Figure 6: Flowchart of the applied algorithm.

When consumers make purchase decisions for products, they need to comprehensively consider the various attributes of the products. Under normal circumstances, it is impossible for every attribute of the product to meet the needs of consumers. Therefore, consumers will only choose to meet their own needs. The required attributes are discarded from other useless attributes. The most common problem in market research is that every product has various attributes such as style, color, brand, and price. Therefore, each attribute corresponds to a different attribute consideration index.

Conjoint analysis happens to be able to resolve. Conjoint analysis firstly makes assumptions about the attributes of commodities and then imitates commodities in real life. Finally, these virtual commodities are displayed to consumers for observation and evaluation, and the effectiveness of such attributes and attribute indicators is evaluated by mathematical statistics. Distinguish, make a quantitative evaluation of the status of each attribute and attribute index in the minds of consumers, and then calculate the utility evaluation value of all commodities by consumers.

Figure 7 is the influence diagram of error parameters. Before calculating the efficacy of all commodities in the minds of consumers, it is necessary to calculate the utility scores of all the attribute indicators combined into this kind of commodities, ideal point model (Ideal Point Model), vector model (Vector Model), and score function model (Path-worth Function Model) are three methods often used in calculations. 


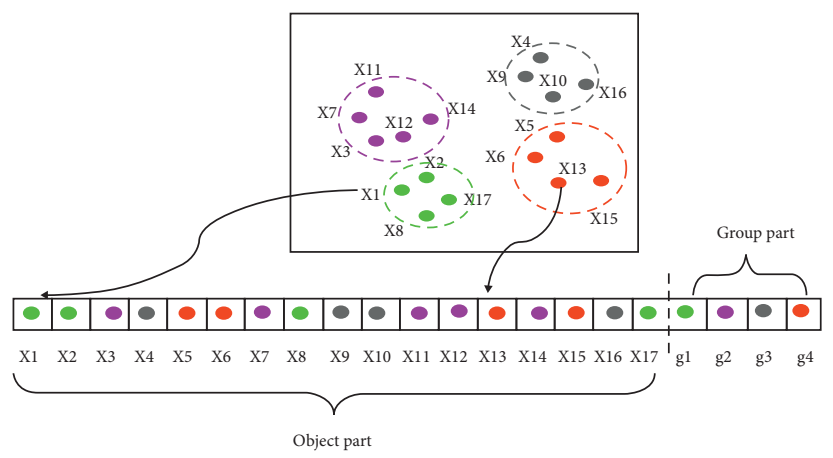

FIGURE 7: Error parameter influence diagram.

TABLE 2: Correlation between various factors.

\begin{tabular}{|c|c|c|c|c|c|c|c|c|c|c|c|c|c|c|c|c|c|}
\hline & $x_{1}$ & $x_{2}$ & $x_{3}$ & $x_{4}$ & $x_{5}$ & $x_{6}$ & $x_{7}$ & $x_{8}$ & $x_{9}$ & $x_{10}$ & $x_{11}$ & $x_{12}$ & $x_{13}$ & $x_{14}$ & $x_{15}$ & $x_{16}$ & $x_{17}$ \\
\hline$x_{1}$ & 1 & & & & & & & & & & & & & & & & \\
\hline$x_{2}$ & 0.1 & 1 & & & & & & & & & & & & & & & \\
\hline$x_{3}$ & 0.2 & 0.1 & 1 & & & & & & & & & & & & & & \\
\hline$x_{4}$ & -0 & 0 & -0.1 & 1 & & & & & & & & & & & & & \\
\hline$x_{5}$ & 0.1 & -0.4 & -0 & -0.1 & 1 & & & & & & & & & & & & \\
\hline$x_{6}$ & -0.1 & 0 & 0.1 & 0.1 & -0 & 1 & & & & & & & & & & & \\
\hline$x_{7}$ & -0.2 & -0.1 & 0.2 & 0 & -0.1 & 0.5 & 1 & & & & & & & & & & \\
\hline$x_{8}$ & -0.2 & -0.5 & -0.1 & 0.1 & 0.4 & 0 & 0.3 & 1 & & & & & & & & & \\
\hline$x_{9}$ & -0.1 & -0.1 & -0 & 0 & 0.2 & -0.2 & 0 & 0.3 & 1 & & & & & & & & \\
\hline$x_{10}$ & -0.2 & -0.2 & -0.1 & 0.1 & -0 & -0.1 & 0 & 0.2 & 0.2 & 1 & & & & & & & \\
\hline$x_{11}$ & -0.2 & -0.3 & -0.1 & 0 & 0.1 & -0.1 & -0 & 0.3 & 0 & 0.3 & 1 & & & & & & \\
\hline$x_{12}$ & 0.2 & 0.5 & 0.1 & 0 & -0.3 & 0.1 & -0.1 & -0.2 & -0.2 & -0.5 & -0.5 & 1 & & & & & \\
\hline$x_{13}$ & -0.1 & -0.2 & -0.1 & 0.1 & 0 & -0.1 & 0.1 & 0.3 & 0.1 & 0.4 & 0.4 & -0.3 & 1 & & & & \\
\hline$x_{14}$ & -0 & 0 & -0 & 0 & -0.1 & -0 & -0.1 & 0 & 0.1 & 0.2 & 0 & -0 & 0.2 & 1 & & & \\
\hline$x_{15}$ & -0.1 & -0.1 & -0 & 0 & -0.1 & 0.1 & -0 & 0.1 & 0.2 & 0.4 & 0.3 & -0.3 & 0.4 & 0.2 & 1 & & \\
\hline$x_{16}$ & -0.1 & 0 & 0.1 & 0 & -0.2 & 0.3 & 0.4 & 0 & -0.1 & 0.1 & 0.2 & 0.03 & 0.2 & 0 & 0.4 & 1 & \\
\hline$x_{17}$ & -0.3 & -0.1 & -0.2 & 0.2 & -0 & 0.3 & -0.1 & -0.1 & 0.3 & 0.3 & 0.4 & 0.37 & -0 & 0.5 & 0.5 & 0.4 & 1 \\
\hline
\end{tabular}

\section{Calculation Results are Analyzed and Discussed}

Table 2 shows the significance test of the influence of each covariate on the overall model. The null hypothesis of this test is that the covariate has no effect on any of the three logs. From the results of the $x_{2}$ test, except for the gift variable, which is not significant, the other covariates are all significant.

Likelihood ratio test of the goodness of fit of the model: usually, we let Ls be the maximum likelihood value estimated by the set model, which reflects the degree to which the sample data are fitted by this model. Figure 8 shows different types of datasets as training samples. In addition, we let Lf be the maximum likelihood value of the full model, where the saturated model is a model that can accurately predict the observed value. Then by comparing Ls and Lf, that is, comparing the predicted value and the observed value, the adequacy of the data represented by the set model can be evaluated. The likelihood ratio statistic (LR) is the logarithm of the ratio of the maximum likelihood value between the set model and the saturated model multiplied by -2 .

When the sample is large enough, this statistic obeys the chi-square distribution, and its degree of freedom is equal to the difference between the number of covariant types in the set model minus the number of coefficients. In the model studied in this article, the degree of freedom of the likelihood ratio statistic is 21 . Because there are 12 covariant types in the data, there are three logit models that need to be fitted, and 15 coefficients need to be estimated, so $12 \times 3-15=21$. Figure 9 shows the histogram of forecasted sales of different luxury goods. The $P$ value corresponding to the likelihood ratio statistic is 0.0711 . This statistic is not significant, indicating that there is no significant difference between the set model and the saturated model, so the fitted model can be accepted.

Based on the previous theoretical analysis, the logit model was tested quantitatively. Since panel data are used, it is first necessary to determine whether to use a fixed-effects model (FE) or a random-effects model (RE). With the help of the Hausman test results, it can be seen that regardless of whether the instrumental variable panel data model is used, the null hypothesis that the fixed-effects and random-effects model estimation results are consistent and the randomeffects model is valid is rejected at a significant level of $1 \%$, so this article selects the fixed-effects model.

From the regression results, each variable passed the $1 \%$ significance test, and the coefficient signs of each variable in different models are consistent, and the economic significance behind it is also consistent. Among them, the coefficient of the variable pcht is negative, 

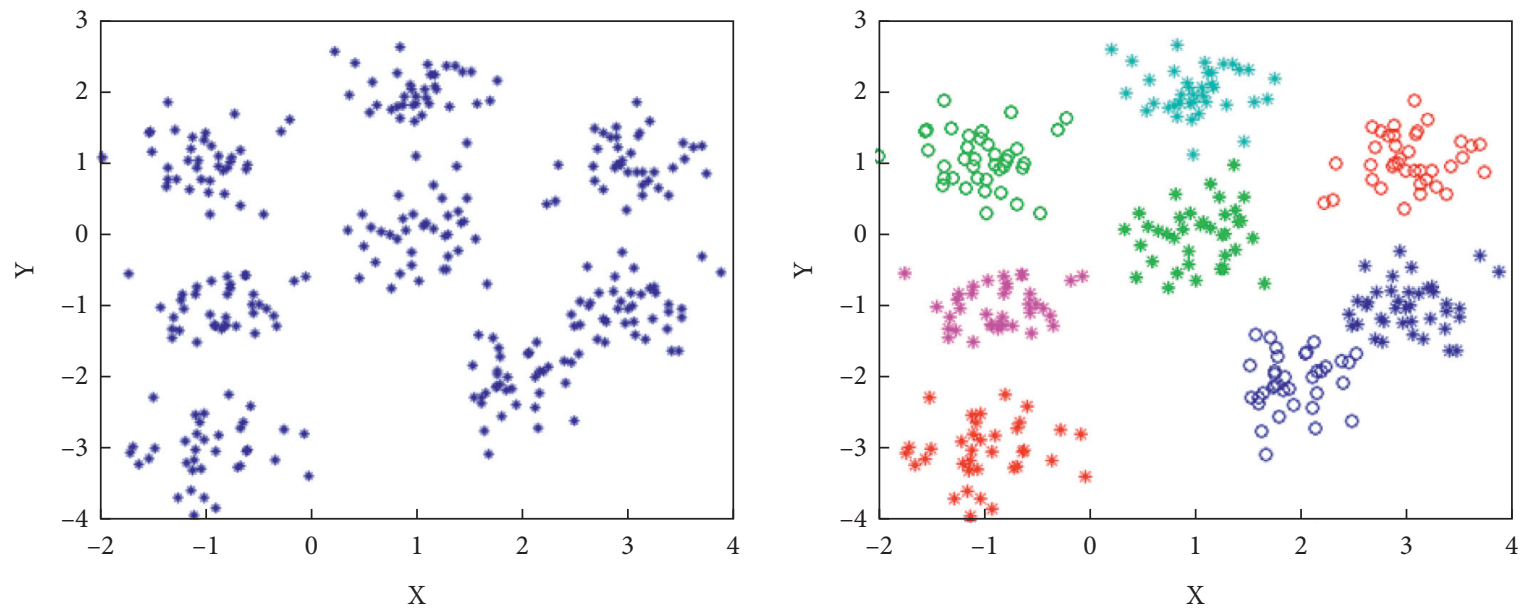

Spheric clusters
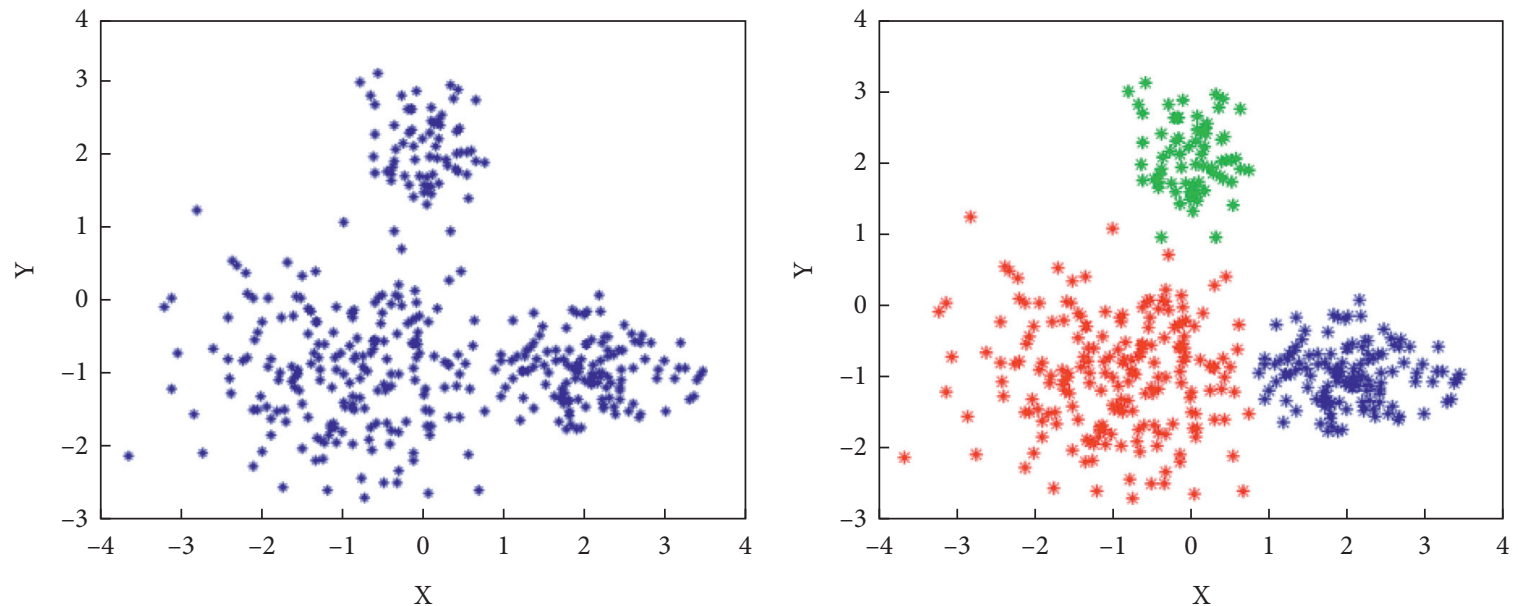

Structured clusters
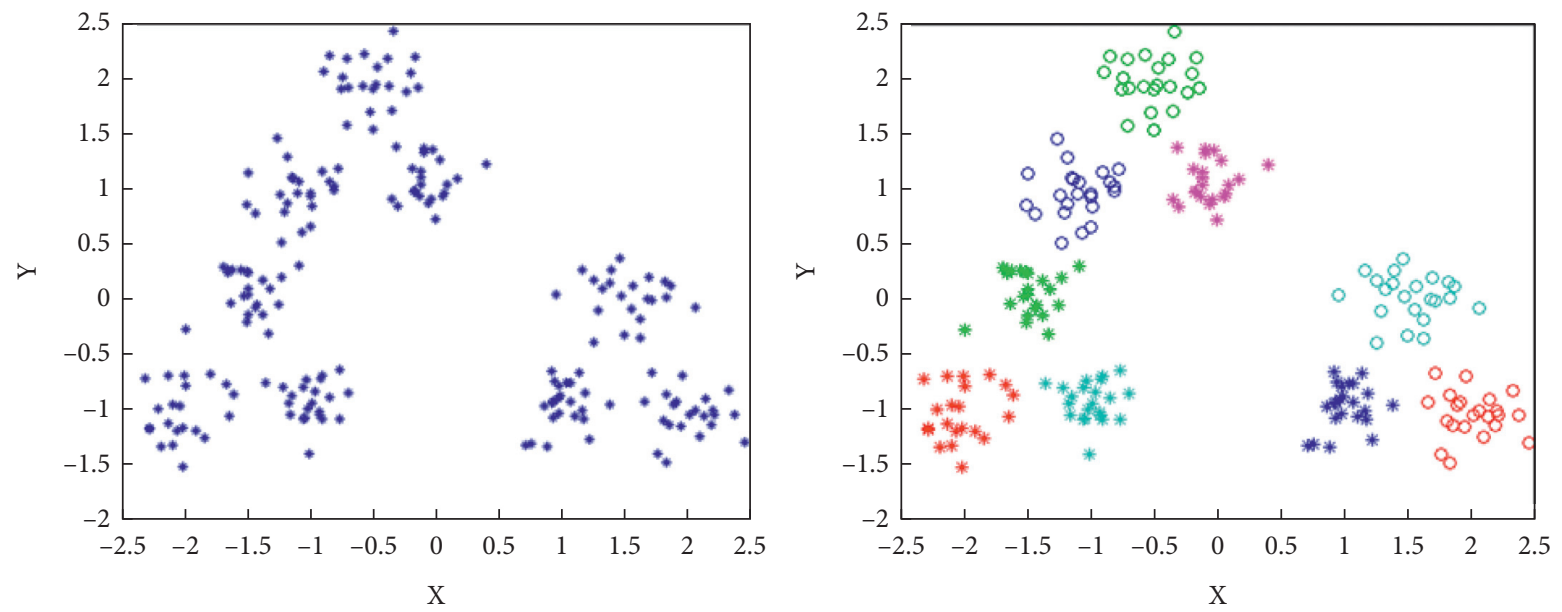

Unbalanced clusters

FIgURE 8: Different types of datasets as training samples.

indicating that the price of luxury goods or its own value has a significant negative impact on the marketing volume of luxury goods. This is because, with the increase of brand prices, there are a large number of substitutes for each brand, which means each expensive brand has a high elasticity of demand, and its price has a negative effect on market share; the coefficient of the variable nscht is positive, which means that the nested market share has a significant positive effect on the relative market share of exported luxury goods, that is, exports. From Figure 10, 


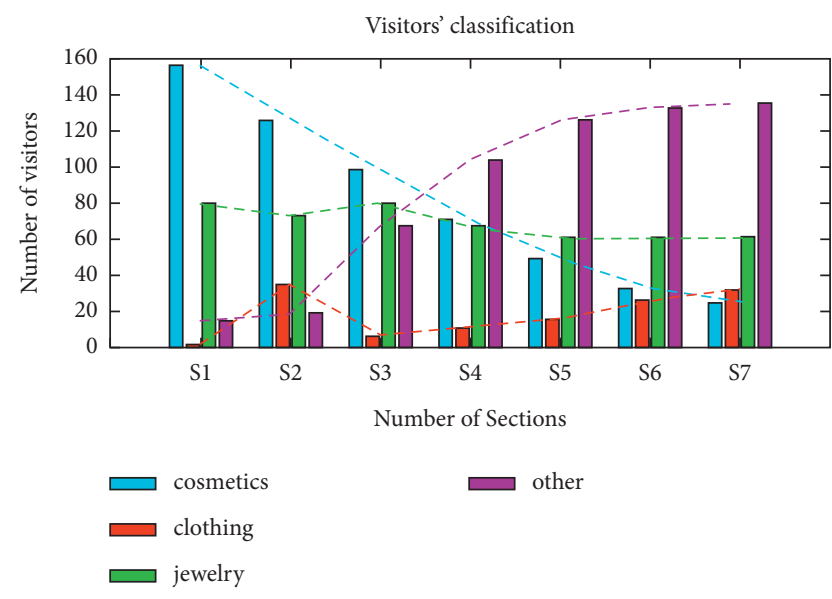

FIGURE 9: Histogram of the forecast sale amount of different luxury goods.

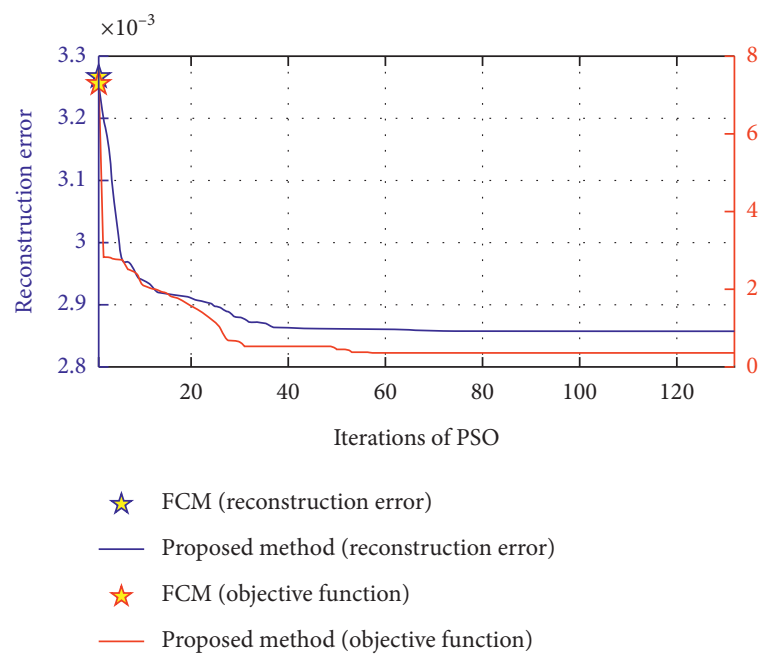

Figure 10: Convergence study on the predicting data.

we can see the pros and cons of the research on the convergence of prediction data. The greater the quantity of a certain product under a certain category exported by a country, the higher the possibility that consumers will choose the product, and the greater the relative market share of the product, which further verifies the rationality of the establishment of the nested theoretical model proposed in the previous article.

\section{The Optimization Algorithm Based on Simulated Data}

Bovy et al. are based on aggregate substitution and GEV models (such as pair-combination logit and cross-nested logit), which add a logarithmic term to the fixed utility in the logit function to modify the utility value.

Usually, we call the heterogeneity that is only related to observable factors as systematic preference difference, and the heterogeneity that includes both observable and unobservable factors is called random preference difference. The hypothesis of consumers' systematic preference difference is that there is a deterministic relationship between preference and observable factors, which is contrary to reality in most cases. Because through the above classification, we know that consumer heterogeneity is inevitably affected by unobservable factors, so a reasonable manifestation of consumer heterogeneity should be random preference differences. This is one of the main reasons why we need to use a hybrid logit model to replace the standard logit model.

Berry's research points out that consumers have a preference for discrete choices. Consumer $i$ chooses products of category $j$ because product $j$ provides consumers with the highest indirect utility. Consumers choose whether to purchase new products to replace the original products on the basis of purchase and whether the utility obtained by this product is greater than the opportunity cost caused by the choice to buy. Therefore, the marketing volume of product $s_{j}$ can be calculated as follows [30]:

$$
s_{j}=\frac{e^{\theta \xi_{j}+\alpha P_{j}+\mu_{j}}}{\sum_{k} e^{\theta \xi_{k}+\alpha P_{j}+\mu_{k}}},
$$

where $\xi_{j}$ represents the observable feature of product $j, p_{j}$ represents the price of product $j, \mu_{j}$ represents the unobservable feature of product $j$, and $\varepsilon_{i j}$ represents consumer $i$ horizontal preference for product $j$.

The improvement of this model makes up for the ignorance of the influence of product level differences within the group on the overall product effect. The introduction of a nested market model can solve the problem of indistinguishable differences in the utility of similar products to consumers.

\section{Conclusion}

The hybrid logit model can provide more consumer information than the standard logit model. For example, as far as the direction of preference is concerned, the standard logit model can only reveal that the average preference of the consumer group for the duration of the contract is negative, so the corresponding business strategy should be to reduce the duration of the contract. The hybrid logit model tells us that $74 \%$ of consumers like short-term contracts, but $26 \%$ of consumers like long-term contracts. Therefore, the corresponding business strategy should be designed according to different consumer groups and the duration of the contract.

The equilibrium solution of a competitive market is ineffective when it is in a situation of positive externalities, and it is prone to "market failure." Based on this, relevant government departments have adopted a series of measures, such as issuing taxation, subsidy policies, bargaining between consumers, and the division of property rights, to reduce the incidence of externalities and achieve optimal social results.

Although most domestic companies have gradually accepted Philip Kotler's customer-oriented marketing art, they are still stuck in the "braining head" in the face of many factors such as diversified customer needs, intensified market competition, and increased market risks. In the "experience" marketing decision-making stage, market 
judgment errors and vicious price wars are not uncommon. The application of quantitative models in luxury marketing research will provide domestic marketing practitioners with more objective and quantitative decision-making information, which will improve the efficiency of domestic corporate marketing management to a certain extent.

\section{Data Availability}

The data used to support the findings of this study are available from the corresponding author upon request.

\section{Conflicts of Interest}

The authors declare that they have no conflicts of interest.

\section{Acknowledgments}

This work was supported by the General Project of Henan Federation of Social Sciences (project name: study on highquality development of county economy in Henan Province, grant no. SKL-2021-2818)

\section{References}

[1] H. M. Kong, A. Witmaier, E. Ko, and A. G. Woodside, "Sustainability and social media communication: how consumers respond to marketing efforts of luxury and non-luxury fashion brands," Journal of Business Research, vol. 131, 2021.

[2] F. Aliyev, T. Urkmez, and R. Wagner, "A comprehensive look at luxury brand marketing research from 2000 to 2016: a bibliometric study and content analysis," Management Review Quarterly, vol. 69, no. 3, pp. 233-264, 2019.

[3] E. Ko, J. P. Costello, and C. R. Taylor, "What is a luxury brand? A new definition and review of the literature," Journal of Business Research, vol. 99, pp. 405-413, 2019.

[4] F. Bachmann, G. Walsh, and E. K. Hammes, "Consumer perceptions of luxury brands: an owner-based perspective," European Management Journal, vol. 37, no. 3, pp. 287-298, 2019.

[5] R. Morgan, "The digital marketing capabilities gap: empirical evidence, managerial shortcomings, and future research streams," Industrial Marketing Management, vol. 90, pp. 276-290, 2020.

[6] L. Busca and L. Bertrandias, "A framework for digital marketing research: investigating the four cultural eras of digital marketing," Journal of Interactive Marketing, vol. 49, pp. 1-19, 2019.

[7] R. Chen and H. Jiang, "Capacitated assortment and price optimization under the nested logit model," Journal of Global Optimization, vol. 77, 2020.

[8] X. Li and J. Ke, "Robust assortment optimization using worstcase CVaR under the multinomial logit model," Operations Research Letters, vol. 47, no. 5, pp. 452-457, 2019.

[9] P. Rusmevichientong and H. Topaloglu, "Robust assortment optimization in revenue management under the multinomial logit choice model," Operations Research, vol. 60, no. 4, pp. 865-882, 2012.

[10] J. Feldman and H. Topaloglu, "Bounding optimal expected revenues for assortment optimization under mixtures of multinomial logits," Production and Operations Management, vol. 24, no. 10, pp. 1598-1620, 2015.
[11] T. Li, "A demand estimator based on a nested logit model," Operations Research, vol. 59, no. 1-2, pp. 107-109, 2019.

[12] X. Peng, C. Lei, and X. Sun, "Comparison of lethal doses calculated using logit/probit-log(dose) regressions with arbitrary slopes using R," Journal of Economic Entomology, no. 3, p. 3, 2021.

[13] M. Aggarwal, "Logit choice models for interactive attributes," Information Sciences, vol. 507, pp. 298-312, 2020.

[14] D. W. Vincent, "The Berry-levinsohn-pakes estimator of the random-coefficients logit demand model," STATA Journal: Promoting Communications on Statistics and Stata, vol. 15, no. 3, pp. 854-880, 2015.

[15] C. R. Knittel and K. Metaxoglou, "Estimation of randomcoefficient demand models: two empiricists' perspective," The Review of Economics and Statistics, vol. 96, no. 1, pp. 34-59, 2014.

[16] E. Sparks, "Compliant digital marketing: making the most of today's tools," ABA Banking Journal, vol. 111, no. 5, pp. 20-21, 2019.

[17] C. Negricea, "Leadership in the new era of human-machine relationships, cultural architecture through digital marketing," Holistic Marketing Management Journal, vol. 11, 2021.

[18] N. Confos and T. Davis, "Young consumer-brand relationship building potential using digital marketing," European Journal of Marketing, vol. 50, no. 11, pp. 1993-2017, 2016.

[19] W. Coreynen, P. Matthyssens, and W. Van Bockhaven, "Boosting servitization through digitization: pathways and dynamic resource configurations for manufacturers," Industrial Marketing Management, vol. 60, pp. 42-53, 2017.

[20] S. Liu, P. Perry, and G. Gadzinski, "The implications of digital marketing on WeChat for luxury fashion brands in China," Journal of Brand Management, vol. 26, 2019.

[21] J. L. Chandon, G. Laurent, and P. Valette-Florence, "Pursuing the concept of luxury: introduction to the JBR special issue on luxury marketing from tradition to innovation," Journal of Business Research, vol. 69, no. 1, pp. 299-303, 2016.

[22] N. Hennigs, K. P. Wiedmann, and C. Klarmann, "Luxury brands in the digital age-exclusivity versus ubiquity," Marketing Review St. Gallen, vol. 29, no. 1, pp. 30-35, 2012.

[23] N. Hennigs, K. P. Wiedmann, C. Klarmann, and S. Behrens, "The complexity of value in the luxury industry," International Journal of Retail \& Distribution Management, vol. 43, no. 10-11, pp. 922-939, 2015.

[24] J. N. Kapferer, "The future of luxury: challenges and opportunities," Journal of Brand Management, vol. 21, no. 9, pp. 716-726, 2015.

[25] T. Li, "A demand estimator based on a nested logit model," Operations Research, vol. 59, no. 1-2, pp. 107-109, 2019.

[26] H. Lai and E. Ng, "On business cycle forecasting," Frontiers of Business Research in China, vol. 14, no. 1, p. 17, 2020.

[27] S. Ng and J. Wright, "Facts and challenges from the great recession for forecasting and macroeconomic modeling," Journal of Economic Literature, vol. 51, no. 4, pp. 1120-1154, 2013.

[28] J. Evermann and T. Mary, "Assessing the predictive performance of structural equation model estimators," Journal of Business Research, vol. 69, pp. 4565-4582, 2016.

[29] S. Chaouch, A. Moussa, I. Ben Marzoug, and N. Ladhari, "Colour recipe prediction using ant colony algorithm: principle of resolution and analysis of performances," Coloration Technology, vol. 135, no. 5, pp. 349-360, 2019.

[30] E. Riza, Y. Tu, J. Benjamas, and M. Lu, "Evaluating credit risk and loan performance in online Peer-to-Peer (P2P) lending," Applied Economics, vol. 47, no. 1, pp. 54-70, 2015. 